\title{
DA HISTÓRIA DO PENSAMENTO POLÍTICO À TEORIA POLÍTICA HISTÓRICA: VARIAÇÕES DA HERMENÊUTICA DO CONFLITO DE QUENTIN SKINNER
}

\author{
Ricardo Silva \\ é professor titular de Teoria Política da Universidade Federal de Santa Catarina (UFSC) e \\ pesquisador do Conselho Nacional de Desenvolvimento Científico e Tecnológico (CNPq). \\ Florianópolis, SC, Brasil. E-mail:<rsilva@cfh.ufsc.br> \\ http://dx.doi.org/10.1590/0102-137171/102
}

\section{Introdução}

Nos debates recentes sobre as modalidades possíveis de elaboração da teoria política, observa-se uma crescente demanda por um estilo de teorização mais atento à historicidade tanto do fenômeno político quanto da própria reflexão teórica sobre a vida política. É fato que esse movimento em prol daquilo que alguns têm denominado "teoria política histórica" (Vincent, 2004) comporta um número considerável de abordagens, ancoradas nas mais diversas tradições intelectuais. No âmbito dessa diversidade, porém, é impossível não reconhecer o protagonismo do contextualismo linguístico, abordagem associada à Escola de Cambridge e à obra de Quentin Skinner, seu mais influente metodólogo.

Se não há dúvida sobre a importância da contribuição de Skinner para atual inflexão historicista no campo da teoria política (Bevir; Adcock, 2007; Palonen, 2002; 2003), ainda há muito a ser dito sobre os modos pelos quais as diversas formulações da metodologia da história intelectual do autor podem subsidiar, no âmbito do multifacetado campo da teoria política contemporânea, a constituição do 
subcampo de uma teoria política informada pela história do pensamento político. O objetivo deste artigo consiste em demonstrar que o compromisso de Skinner com a "teoria política histórica" vai adquirindo consistência com o passar do tempo, tornando-se inequívoco apenas nas posições mais recentes do autor.

Argumenta-se que os principais ensaios metodológicos de Skinner, publicados entre meados dos anos 1960 e começo dos anos 1970, mediante os quais formalizou-se e difundiu-se a abordagem contextualista, prescreviam uma clara distinção entre os campos disciplinares da história do pensamento político e da teoria política contemporânea. Tal linha divisória entre filosofia e história tinha o efeito de inibir um esforço mais consistente de justificação do projeto de uma teoria política historicamente informada. Ver-se-á que as fronteiras então estabelecidas representavam antes a formalização de esforços substantivos de investigação his138 tórica realizados na fase de germinação e surgimento da Escola de Cambridge do que um programa destinado a enquadrar pesquisas futuras. Ou seja, parte considerável do que se convencionou denominar "contextualismo linguístico" refletia com mais fidelidade a prática já realizada entre as décadas de 1950 e 1960 do que a que viria a realizar-se a partir de então.

Seria injustificável exagero afirmar que, com o passar dos anos e o enfrentamento da crítica, Skinner abandonou por completo suas proposições iniciais. Como veremos, considerações de fundo sobre o pensamento político enquanto expressão da ação linguística, bem como sobre o papel do conflito ideológico na tarefa de compreender o que os autores "estavam fazendo" ao escreverem seus textos, tão caras às primeiras formulações da metodologia contextualista, permanecem no núcleo da visão skinneriana da política. Contudo, tanto seus trabalhos substantivos quanto suas mais recentes e esparsas declarações sobre teoria e método, 
geralmente feitas em entrevistas, sugerem que estamos diante de uma revisão do contextualismo radical de suas posições originais e, ao mesmo tempo, mais próximos de uma abordagem mais compatível com o projeto de incorporação do historicismo na teoria política.

$\mathrm{O}$ artigo divide-se em três seções. Primeiro, examino o momento de emergência do contextualismo linguístico, procurando mostrar a sintonia da nova metodologia com estudos históricos substantivos realizados por Skinner na década de 1960. Em seguida, aponto os primeiros sinais de ultrapassagem do método contextualista na pesquisa realizada ao longo dos anos 1970, consubstanciada especialmente em As fundações do pensamento político moderno. Por último, procuro mostrar como, a partir da década de 1980, com a evolução de sua pesquisa sobre a tradição republicana, Skinner passa a mobilizar os termos da arqueologia e, mais recentemente, da genealogia para justificar sua nova síntese entre a história do pensamento político e a teoria política normativa.

\section{0 contextualismo e suas origens}

Se fôssemos atribuir a um único texto a celebridade alcançada pelo método associado à Escola de Cambridge, este seria sem dúvida o artigo Significado e compreensão na história das ideias. A peça foi publicada em 1969, no oitavo volume de um periódico que, naquela época, estava longe de desfrutar da liderança que passou a ter nas décadas seguintes. Até receber a acolhida de History and Theory, o longo e beligerante artigo de cinquenta páginas foi rejeitado por vários periódicos do mainstream acadêmico. Skinner (2002a, p. 214) confessa que teve "imensa dificuldade em publicá-lo" - e o texto soava ainda mais desafiador quando se levava em conta que seu autor era um scholar ainda na casa dos vinte anos de idade. 
Como o próprio autor reconheceria poucos anos depois da publicação de Significado e compreensão, o tom "abertamente polêmico" do artigo, pelo qual ele se dizia "moderadamente arrependido", tinha como "principal preocupação expor as fragilidades de duas suposições prevalecentes no estudo da história do pensamento político" (Skinner, 1974, p. 279). A primeira era a suposição de que a compreensão de certos textos, especialmente de autores clássicos, requeria uma atenção exclusiva ao próprio universo do texto, sem que o comentador precisasse ater-se ao contexto de enunciação do autor estudado. A segunda era a suposição de que uma história satisfatória poderia ser construída a partir de "ideias-unitárias" contidas nos textos ou, ainda, "ligando tais textos em uma cadeia de supostas influências" (Skinner, 1974, p. 279) ${ }^{1}$.

É verdade que as suposições apresentadas foram os principais alvos da polêmica de Skinner, que as classificou como erros típicos da abordagem "textualista” na história das ideias. Contudo, a parte crítica do artigo em questão comportava também o ataque a uma modalidade de contextualismo concentrado na reconstrução do contexto social do texto a ser interpretado. Nessa segunda vertente, que podemos denominar de "contextualismo sociológico", encontravam-se não apenas as análises marxistas centradas numa noção epifenomênica de ideologia, como também abordagens derivadas da sociologia do conhecimento e aquela associada à obra do historiador inglês Lewis Namier. A chave explicativa desse tipo de abordagem era a compreensão do pensamento político como um epifenômeno das relações sociais de determinada época histórica. As ideias e

\footnotetext{
${ }^{1}$ Como se sabe, a prática da história das ideias baseada no isolamento e análise das "ideias-unitárias" (unit-ideas) é a marca registrada de Arthur Lovejoy e sua escola. Lovejoy foi o fundador e primeiro editor do influente periódico Journal of the History of Ideas, editado ininterruptamente desde 1940. A principal aplicação da abordagem de Lovejoy encontra-se no livro The great chain of being, de 1936.
} 
representações da vida política assumiam o status de reflexos das relações materiais ou de racionalizações a posteriori de interesses e valores de classes e grupos sociais. Contra esse tipo de contextualismo, Skinner asseverava que "mesmo que o estudo do contexto social pudesse servir para explicar os textos, isso não seria a mesma coisa que prover os meios para compreendê-los" (Skinner, 1969a, p. 46, grifo do autor). O contextualismo sociológico seria defensável no âmbito ciências sociais, cujas disciplinas são voltadas à explicação causal dos fenômenos, mas seria no mínimo insuficiente para a realização da tarefa do historiador, especialmente do historiador das ideias, um especialista ocupado primordialmente com a compreensão do significado hermenêutico de seu objeto.

Seja como for, era mesmo contra o "textualismo" que Skinner voltava suas principais energias. Ele lamentava que as abordagens textualistas, empenhadas em revelar o significado de um texto mediante o simples procedimento de ler e reler o texto "vezes e vezes sem conta" (Skinner, 1969a, p. 32), eram bem mais propensas a gerar "mitologias" do que genuína história. As mais comuns eram a mitologia da doutrina e a mitologia da coerência, embora Skinner também atribuísse ao procedimento textualista outros resultados espúrios, como as mitologias da prolepse e a do parioquialismo (Skinner, 1969a, p. 22; p. 24). A consequência comum de todas essas mitologias é o erro de atribuir a um autor do passado valores, conceitos e mesmo termos que o autor em questão não apenas não professou ou mobilizou, mas que sequer poderia fazê-lo, dada a indisponibilidade de tais representações no contexto histórico de efetuação da ação linguística. Descrever o passado com o emprego do vocabulário do presente teria como resultado interpretações anacrônicas e "historicamente absurdas" (Skinner, 1969a, p. 7). De modo a evitar o anacronismo, seria preciso descrever o passado nos termos do próprio passado. 
Skinner considerava uma limitação injustificável o fato de que a história das ideias de orientação textualista elegesse como objeto de investigação exclusivamente os autores clássicos, supostamente os únicos dignos da atenção do historiador. Conforme afirma em uma de suas inúmeras passagens destinadas a demarcar a fronteira entre história e filosofia, "as qualidades de inteligência e apresentação que fazem de um autor a melhor ilustração em um quadro filosófico farão dele a pior ilustração em um quadro histórico" (Skinner, 1966a, p. 213). Para Skinner, esse enquadramento tipicamente filosófico na história das ideais orientava-se pelo errôneo princípio de que os textos que consideramos clássicos contém repostas para "problemas perenes" da vida social e política. Ele é bastante enfático ao afirmar que as implicações de sua crítica não se limitam a constatar o fato mais ou menos óbvio de que "os textos clássicos não poderiam estar preocupados com nossas perguntas e respostas"; 142 além disso, seria preciso reconhecer que, na história do pensamento político, tudo o que há são "respostas individuais para questões individuais, e tantas questões quantos são os questionadores". Em suma, não há qualquer esperança em encontrar a justificação para a história das ideias "na tentativa de aprender diretamente com os autores clássicos, focalizando suas respostas para questões supostamente atemporais" (Skinner, 1969a, p. 50).

A rejeição explícita do status dos autores clássicos como fonte de ensinamentos "diretos" para a teoria política contemporânea tem motivado um amplo conjunto de reações, animando um intenso debate metodológico ao longo das últimas décadas (Silva, 2010). O método contextualista foi objeto das mais variadas objeções, a ponto de Skinner, em um longo texto de resposta a seus críticos, confessarse "perplexo por aprender", que é, ao mesmo tempo, "um idealista, um materialista, um positivista, um relativista, um antiquarista, um historicista, e um mero metodólogo com 
nada de substancial a dizer" (Skinner, 1988, p. 231). Desse amplo conjunto de objeções, muitas delas mutuamente excludentes, a acusação "antiquarismo" é a que mais interessa para os fins deste artigo. Aplicado em denunciar o desvio do anacronismo, anátema das abordagens textualistas, Skinner expõe-se em demasia à crítica que denuncia o erro oposto. Mas a acusação de reduzir a história intelectual a uma atividade de antiquário, em que o estudo do passado provar-se-ia irrelevante para a inteligência do presente, tem sido enfaticamente rechaçada pelo autor. No primeiro volume de Visões da política, uma reedição de seus principais ensaios de método, ele afirma ter "previsto essa objeção depressivamente filistina", e lamenta que suas primeiras tentativas de resposta "estiveram longe do suficiente para satisfazer meus críticos" (Skinner, 2002c, p. 6).

Mas o fato é que o deslocamento da centralidade dos clássicos, combinado à rejeição da crença na existência problemas perenes na história do pensamento político, impele Skinner a buscar outras vias de justificação do estudo da história como uma atividade potencialmente iluminadora do presente. Vale dizer: o autor empenha-se em refutar a acusação de antiquarista, mas o faz promovendo a relativização do contextualismo radical de seus ensaios metodológicos. Deixemos para adiante a indicação de suas respostas para a pergunta sobre a atualidade do estudo do passado. Vejamos antes de que modo a metodologia contextualista surge como esforço de formalização de uma prática que lhe é anterior.

De fato, a prática geradora da metodologia contextualista iniciara-se pelo menos uma década antes de sua plena expressão teórica. Neste particular, o principal mérito cabe a Peter Laslett, inspirador não apenas de Skinner, mas de toda a primeira geração de metodólogos de Cambridge. J. G. A. Pocock, por exemplo - outro expoente da Escola de Cambridge -, refere-se a Laslett como o "protagonista", um 
"homem extraordinário" que "deslanchou uma revolução local cujos efeitos foram sentidos por muitos anos" (Pocock, 2004, p. 535). Afirma, também, que seu próprio livro de estreia, The Ancient constitution and the feudal law, de 1957, foi escrito sob a influência do trabalho que vinha sendo desenvolvido por Laslett desde o fim da década de 1940.

Skinner, que teve Laslett como seu tutor informal em Cambridge, é ainda mais enfático ao atestar o pioneirismo do mestre, reiterando que achou "maravilhosa, em vários sentidos", sua introdução à reedição de Dois tratados sobre o governo, tanto pela elegância do texto quanto pelas descobertas sobre Locke que lhe pareciam "metodologicamente interessantes" (Skinner, 1997, p. 69; 2002a, p. 214). A introdução a que se refere Skinner consiste num texto de mais de 150 páginas, em que Laslett, baseado em documentação inédita proveniente da biblioteca de Locke, investe contra uma série de mitos prevalecentes na interpretação de Dois Tratados. 144 Cruzando informações extraídas de diferentes versões dos manuscritos da obra, da correspondência de Locke com seus interlocutores, da leitura de seus diários e das datas de aquisição dos livros que compunham sua biblioteca, Laslett foi capaz de estabelecer o período exato de composição do texto. Embora tenha sido publicada apenas em dezembro de 1689, ano da Revolução Gloriosa, a obra foi escrita entre 1679 e 1680, uma década antes do evento que selou o fim da monarquia absolutista na Inglaterra. Com esse prosaico achado, caía por terra a influente interpretação segundo a qual Dois tratados seria fruto de um esforço de racionalização e justificação da revolução. Afinal, como seria possível racionalizar ou justificar um evento que só ocorreria em um futuro relativamente distante naquela Inglaterra de tempos conturbados e acelerados?

Pouco depois de proclamar uma espécie de epitáfio provisório da teoria política, com a declaração de que "no momento [...] a filosofia política está morta" (1956, p. vii), 
Laslett, na introdução ao texto de Locke, assentava as bases da metodologia contextualista. Sua receita para a correta interpretação de Dois tratados girava em torno da sugestão de que "nosso primeiro propósito deve ser um modesto exercício de historiador - estabelecer os textos de Locke como ele gostaria que fossem lidos, fixá-los em seu contexto histórico, no próprio contexto de Locke" (Laslett, 1960, p. 4). Eis uma sugestão que também pode ser lida como um esforço de demarcação da fronteira entre o trabalho do historiador e o trabalho do teórico, além de servir de condenação da prática de fazer dos textos clássicos meros veículos de justificação das crenças do intérprete. Conforme observa um crítico moderadamente simpático à Escola de Cambridge (Bevir, 2009, p. 214), Laslett e outros historiadores britânicos de sua geração, devotados em "transformar a história de um romance vitoriano em uma disciplina profissional", revelavam em sua prática a influência do positivismo lógico e de um estilo modernista de produção de conhecimento, este caracterizado pela crença de que "devemos responder questões sobre política menos por meio da filosofia que da ciência social empírica e da nova história das ideias”. Uma consequência dessa crença era a mudança da própria identidade e do papel atribuídos aos filósofos políticos, que "apareciam menos como pessoas a procura de uma metafísica compreensiva e mais como pessoas expressando visões normativas, mais ou menos do mesmo modo que outros cidadãos e políticos".

O tipo de investigação que Laslett realizou em relação a Locke, Skinner decidiu fazer em relação a Hobbes. Segundo o próprio Skinner, tal decisão foi tomada a despeito do ceticismo de seu tutor:

A atenção que Laslett me deu naquela época foi da maior importância [...] Eu me lembro de ter conversado com ele sobre sua nova edição de Locke e foi assim que percebi que 
ele tinha uma ideia bastante estranha sobre o que tinha realizado com seu trabalho. Ele considerava que o que tinha conseguido era mostrar que, em vez de textos arquitetônicos de política, com bases em premissas filosóficas, os textos de Locke eram pièces d'occasion. Mas ele ainda parecia pensar em Hobbes como um autor cujo sistema de política poderia ser avaliado independentemente de seu contexto histórico. O problema era que o trabalho do próprio Laslett havia me persuadido de que, ao contrário do que ele próprio parecia acreditar, tal tipo de investigação poderia ser feito em relação a qualquer texto filosófico (Skinner, 2002a, pp. 217-218).

Assim, antes de publicar seus textos metodológicos, Skinner publicou uma série artigos sobre Hobbes (Skinner, $1964 ; 1965 ; 1966 b ; 1966 c ; 1969 b)$. Tudo indica que a formalização do método foi ocorrendo à medida que a pesquisa 146 sobre o contexto ideológico de Hobbes progredia. A primeira peça dessa pesquisa, e também o primeiro texto publicado da longa e prolífica carreira do autor, foi uma extensa resenha crítica de obras então recém-publicadas sobre o Leviatã. $\mathrm{O}$ ataque mais incisivo era desferido contra F. C. Hood, que acabara de lançar The divine politics of Thomas Hobbes: an interpretation of Leviathan (1964), mas a crítica alcançava também contribuições de outros estudiosos de Hobbes, tais como Howard Warrender, S. I. Mintz e C. B. MacPherson. Embora chegando a conclusões distintas sobre a doutrina supostamente professada na filosofia política de Hobbes, tais autores "estão todos preocupados em reduzir Hobbes à coerência em virtude de uma teoria sobre os 'reais' pressupostos de seu pensamento" (Skinner, 1964, p. 322). O caso de Hood é apresentado como exemplar, pois "indica a maneira pela qual as exposições das próprias teorias políticas tendem a tornar-se exercícios filosóficos", fomentando uma abordagem que depende de 
"ignorar qualquer elemento de condicionamento histórico na maneira de Hobbes apresentar suas visões" (Skinner, 1964, p. 330). Além disso, tal abordagem ignora que um "estudo propriamente histórico da teoria política" requer a incorporação de "alguma visão da teoria política como uma atividade social". Em suma, se o que se deseja é "clarear as confusões" presentes nos estudos sobre a obra de Hobbes, o que se precisa "é menos de filosofia e mais de história" (Skinner, 1964, p. 333).

E é exatamente com esse propósito de tornar mais histórico e menos filosófico o estudo da teoria política que Skinner dedica seus primeiros esforços de historiador profissional à obra do mais importante filósofo político inglês. Na perspectiva então defendida pelo autor, tornar mais histórico o estudo da teoria política equivalia a pôr em prática uma abordagem orientada à reconstituição do "contexto ideológico" em que os autores do passado escreveram seus textos. Sem o trabalho de contextualização seria impossível compreender o significado histórico do texto, ou seja, não haveria meios de apresentar uma hipótese sobre a intenção autoral subjacente à ação linguística. Assim, tampouco seria possível identificar o que um autor do passado "estava fazendo" ao escrever determinado texto.

As inúmeras peças publicadas sobre Hobbes e sobre o contexto da revolução inglesa, entre meados dos anos 1960 e o início da década seguinte, formam, portanto, um conjunto destinado a duas tarefas: refutar as interpretações dominantes sobre esses temas e dar corpo à interpretação contextualista. A meu ver, esse conjunto de estudos substantivos espelha as prescrições metodológicas de Skinner muito mais fielmente do que os estudos de fases posteriores de sua obra. Os artigos destinados a mostrar a profunda imersão de Hobbes no debate intelectual e político de sua época são exemplares do esforço de aplicação do método contextualista. 
Os alvos de Skinner eram as interpretações que concebiam Hobbes como uma espécie de filósofo aprisionado em seu grandioso sistema arquitetônico e isolado das contendas ideológicas da época. De um modo geral, Hobbes aparecia como um filósofo destinado a exercer enorme influência em épocas posteriores, mas amplamente ignorado em sua própria época. Além disso, era tido como alguém que se movia no âmbito de um diálogo silencioso com a grande tradição, mas que preferia manter-se distante das opiniões de seus contemporâneos. Nesse tipo de interpretação, tudo o que interessava ao filósofo era o refinamento de seu sistema e a apresentação definitiva de sua inovadora doutrina. Skinner procura mostrar o contrário. Não apenas Hobbes estava atento às ideais que circulavam entre a intelectualidade de sua época, mas também seus contemporâneos estavam profundamente interessados nas ideias de Hobbes.

Em outro texto de sua primeira lavra, Skinner detém148 -se na relação de Hobbes com a prestigiosa Royal Society, instituição criada em 1660 para, presumidamente, reunir as mais notáveis personalidades do mundo científico (Skinner, 1969b). Por que razão uma personalidade da estatura de Hobbes jamais tornou-se fellow daquela instituição? Essa era a questão que inquietava Skinner, e que havia inquietado outros historiadores antes dele. Como de hábito, Skinner não oferece sua resposta à questão sem antes objetar as respostas de seus antecessores. Não teriam sido as crenças religiosas - ou ausência delas - de Hobbes, como sustentavam alguns intérpretes, a causa da exclusão do autor da plêiade londrina. A despeito da hegemonia puritana na Royal Society, outros intelectuais, até mais suspeitos de ateísmo, dela fizeram parte, inclusive na condição de fundadores. Também não se poderia atribuir tal exclusão ao fato de Hobbes desposar um modelo mecanicista de ciência, já considerado ultrapassado pela vanguarda da comunidade científica da época, pois a maioria dos representantes da 
nova ciência também não encontrava o reconhecimento da instituição que desdenhou Hobbes.

Ao contestar as interpretações anteriores, Skinner lança luz não apenas sobre o diálogo entre Hobbes e seus contemporâneos, mas também revela algo da natureza da própria Royal Society, lançando dúvidas quanto à medida em que a instituição era realmente destinada a reunir os mais destacados homens de ciência da época. Analisando evidências encontradas em cartas de Hobbes a membros da associação, além de cartas que estes trocavam entre si, Skinner conclui que, em conjunto, "esses fatos sugerem um paradigma" totalmente diferente para a compreensão da fase inicial da Society e da sua natureza: "nem uma academia puritana, e nem o centro consciente de todo esforço genuinamente científico, porém algo muito mais parecido com um clube de cavalheiros" (Skinner, 1969b, p. 238). O espírito crítico e inquisidor subjacente a declarações encontradas nas cartas de Hobbes sobre a obra de membros da Associação indicava ao conjunto dos fellows que o autor de Leviatã pouco se adaptava à natureza do clube. Afinal, como observa Skinner, "ninguém quer encorajar um clube entediante". No fim das contas, a exclusão de Hobbes e de tantos outros cientistas devia-se ao fato de que "eles simplesmente não vinham a pertencer ao mesmo grupo social que decidiu formar o clube" (Skinner, 1969b, p. 238).

Para Skinner, os fatos sugeriam que a crença difusa na ausência de inserção de Hobbes no debate ideológico de sua época era completamente insustentável. O filósofo viveu o bastante para presenciar o surgimento tanto de seguidores quanto de detratores de suas ideias. Além de documentar o intercâmbio intelectual entre Hobbes e grandes personalidades do continente europeu, como Descartes e intelectuais do círculo de Mersenne, iniciado ao longo de seu exílio de mais de uma década em Paris e continuado após seu retorno a Londres em 1651 (Skinner, 1966b), 
Skinner evidencia que o interesse na obra do filósofo era significativo também na Inglaterra. É verdade que o respeito pelas contribuições científicas de Hobbes era bem maior na "república das letras" continental do que entre a intelligentsia da terra natal do filósofo. Isso, contudo, não preveniu o fenômeno da crescente popularidade que sua doutrina alcançaria ainda em seu tempo de vida.

No artigo intitulado "O contexto ideológico do pensamento de Thomas Hobbes", uma das aplicações mais exemplares do método contextualista, Skinner reúne considerável volume de informações para refutar a mitologia criada em torno de um Hobbes supostamente isolado de seu ambiente intelectual. $\mathrm{O}$ autor atribui tal mitologia a uma leitura que tem "concentrado demasiada atenção no texto do próprio Hobbes" e negligenciado qualquer tentativa de "estudo das relações entre seu pensamento e sua época", sobretudo "suas afinidades com outros escritores políticos 150 de seu tempo" (Skinner, 1966c, p. 286). E embora parte da literatura registre a numerosa quantidade de opositores que o filósofo despertou entre intelectuais ingleses, a maioria dos intérpretes peca por não perceber que "o que perturbava os críticos era não somente a séria reputação ou mesmo o conteúdo alarmante das doutrinas de Hobbes, mas sua força ideológica e mesmo sua alarmante popularidade" (Skinner, 1966c, p. 294). O que mais poderia explicar o surgimento de tão numerosos e ardentes inimigos de um escritor político se não a existência de igualmente numerosos e ardentes seguidores? Com a reconstituição do contexto ideológico de Hobbes, Skinner ilumina os contornos de uma corrente doutrinária cujo próprio nome atesta a influência exercida pelo autor de Leviatã já na segunda metade do século XVII. Embora o próprio Hobbes não descuidasse de manter-se a segura distância dos perigosos propagandistas do "hobbismo", estes encontravam nas obras do filósofo elementos para advogar um tipo de governo que seus opositores 
entendiam como selvagem, arbitrário e com disposições ateísticas (Skinner, 1966c, p. 296).

Em suma, na pesquisa de Skinner sobre Hobbes, conduzida na década de 1960, o método contextualista tem sua mais completa aplicação. Ao fazer em relação a Hobbes o que Laslett fez em relação a Locke, Skinner evidenciou que mesmo os mais sistemáticos e abstratos pensadores políticos se encontram irremediavelmente envolvidos nas contendas intelectuais de suas próprias épocas. Uma miríade de autores e atores esquecidos ou mesmo nunca antes lembrados entra em cena. Com isso, o pano de fundo para a interpretação dos textos de Hobbes deixa ser uma espécie de deserto em que figuram apenas os conceitos do filósofo e esporádicas aparições de outros gigantes da tradição, tornando-se algo mais próximo da natureza conflituosa da vida política.

\section{Além do contextualismo}

Ainda enquanto secava a tinta de suas reflexões sobre método e de seus primeiros estudos substantivos, o próprio Skinner incumbiu-se de ultrapassar algumas das fronteiras disciplinares demarcadas por ele e por seus colegas de Cambridge. Se as prescrições metodológicas do contextualismo linguístico espelhavam com certa acurácia seus primeiros estudos históricos, elas tornaram-se menos apropriadas para a descrição de sua prática subsequente. Desde As fundações do pensamento político moderno, até seus estudos mais recentes sobre a tradição republicana, o que se tem observado é um progressivo afastamento das regras mais restritivas ao intercâmbio entre história e teoria política.

Fundações guarda uma relação ambígua com a metodologia contextualista. Embora a obra tenha sido publicada apenas em 1978, sua redação iniciou-se no limiar daquela década, imediatamente após Skinner ter produzido e publicado seus principais ensaios metodológicos. Como vimos, as prescrições metodológicas de Skinner são uma espécie 
de consequência teórica de sua primeira fase de estudos substantivos sobre Hobbes e a revolução inglesa. Mas agora podemos acrescentar que elas são também o ponto de partida para sua obra prima. Referindo-se, retrospectivamente, à própria intenção ao escrever a obra, Skinner esclarece que "quando me voltei a escrever Foundations em 1972, foi basicamente com a intenção de usar um amplo quadro para ilustrar algumas das conclusões metodológicas e mesmo filosóficas às quais eu havia chegado" (Skinner, 2006, pp. 239240, grifo meu).

É sintomático que Skinner tenha se referido a "algumas" de suas conclusões metodológicas, não a todas. Parece-me justificável, ao menos em certa medida, a afirmação de um de seus críticos de que "se Skinner tivesse seguido suas próprias prescrições, As fundações do pensamento político moderno teria tido de assumir uma forma muito diferente" (Boucher, 1985, p. 242). Creio, porém, ser mais apropriado afirmar 152 que se, por um lado, a obra supera a metodologia, por outro, ela realiza fielmente a filosofia que antecede logicamente o método.

Uma das principais prescrições da metodologia contextualista de Skinner é o procedimento de recuperação da intenção autoral subjacente à ação linguística. O trabalho de reconstituição do contexto das convenções linguísticas que circunscreve o ato de escrever é um procedimento ancilar à interpretação do texto, mas a meta final do historiador deveria ser a formulação de uma hipótese plausível sobre o que o autor "estava fazendo" ao escrever. Para Skinner, "a metodologia apropriada para a história das ideias" deve compreender dois momentos: primeiro, "delinear o leque completo de comunicações que poderiam ter sido convencionalmente realizadas em dada ocasião"; segundo, "traçar as relações entre dado proferimento e este contexto linguístico mais amplo como um meio de decodificar a real intenção do autor em questão" (Skinner, 1969a, p. 49). 
Ou seja, compreender o significado histórico de um texto equivale a revelar o "ponto" de um ato linguístico, sua força como ação, o que só é possível com a recuperação da intenção do autor ao escrever o texto.

Mas essa ênfase na intenção ilocucionária do ato linguístico, apresentada na forma de síntese da filosofia da linguagem de Austin com a filosofia da história de Collingwood, parece pouco relevante em Fundações. A despeito de Skinner anunciar, no prefácio da obra, que "o procedimento aqui exposto" permite definir o que os autores "estavam fazendo" quando escreveram seus textos, e que isso equivale a "compreender algumas de suas intenções básicas ao escrever" (Skinner, 1996, p. 13), o fato é que a noção de intenção autoral não ocupa centralidade na obra. É verdade que Skinner atribui intenções a muitos dos protagonistas de sua narrativa. Assim, Bartolo "partiu da intenção explícita de reinterpretar o código civil romano com o objetivo de proporcionar às comunas lombardas e toscanas uma defesa legal, e não apenas retórica, de sua liberdade contra o Império" (Skinner, 1996, p. 31). Marsílio de Pádua, em seu Defensor da paz, tinha a intenção de proporcionar "a sustentação ideológica de que as cidades repúblicas do Regnum ltalicum mais necessitavam naquele momento" (Skinner, 1996, p. 40). Já "Maquiavel pôde ter a intenção de questionar, ou mesmo ridicularizar" alguns dos valores dos humanistas que o precederam (Skinner, 1996, p. 150). Bodin, nos Seis livros da república, tinha como intenção e também como sua "principal tarefa ideológica [...] atacar e refutar a teoria da resistência dos huguenotes" (Skinner, 1996, p. 556).

Todavia, as intenções atribuídas a esses e outros pensadores assumem um grau de generalidade incompatível com a especificidade que é dada à noção de intenção ilocucionária na teoria dos atos de fala: primeiro pelo fato de Skinner extrapolar o campo de aplicação da teoria de Austin e seus seguidores, mobilizando para a compreensão do significado 
de textos escritos o aparato conceitual criado para a compreensão de situações dialógicas face a face ${ }^{2}$; segundo pelo fato de Skinner atribuir uma intenção singular não apenas a proferimentos individualizados e realizados num único ato, mas também a proferimentos bem mais complexos e articulados ao longo do tempo. Assim, intenções ilocucionárias são atribuídas em função de conteúdos presentes em livros inteiros, no conjunto da obra de determinados autores ou mesmo em toda uma corrente de autores e atores políticos comprometidos com determinada causa.

Ampliando-se o campo de aplicação do conceito de intenção ilocucionária, tem-se como contrapartida uma classificação mais generalizante das intenções possíveis. Em Fundações, o leque de intenções possíveis resume-se a dois tipos básicos: intenções legitimadoras e intenções deslegitimadoras. Ou seja, a resposta para a pergunta sobre o que os autores estavam fazendo ao escreverem seus textos reside sempre em saber se os autores de textos políticos estavam ocupados em naturalizar, elogiar, racionalizar e justificar instituições e cursos de ação política ou, alternativamente, em desnaturalizar, criticar, ridicularizar e repudiar tais instituições e cursos de ação. Como observa Boucher (1985, p. 223), "Fundações demonstra que o foco da atenção histórica de Skinner é predominantemente sobre os estilos de legitimação, ou ideologias, e só incidentalmente sobre a recuperação de intenções".

2 O filósofo Paul Ricoeur advoga a inviabilidade de aplicação da teoria dos atos de fala à interpretação de textos escritos ao afirmar que "com o discurso escrito, a intenção do autor e o significado do texto cessam de coincidir. Esta dissociação entre o significado verbal do texto e a intenção mental é o que está realmente em questão na inscrição do discurso. Não que possamos conceber um texto sem um autor; a ligação entre o autor e o discurso não é abolida, mas distendida e complicada. [...] a carreira do texto escapa ao finito horizonte vivido por seu autor" (Ricoeur, 1979, p. 78). Críticas ao método de Skinner inspiradas nos argumentos de Ricoeur podem ser verificadas em Boucher (1985, p. 228-229; 1986), Seidman (1983, p. 84), Harlan (1989) e Feres Júnior (2005). 
Além de não atribuir centralidade ao procedimento de recuperação das intenções ilocucionárias, Fundações distancia-se das prescrições originais do contextualismo linguístico em outro ponto importante. Em várias ocasiões, Skinner expressou seu ceticismo a respeito da possibilidade de se tomar ideias e conceitos enquanto tais como o foco de interesse da história intelectual. Na conclusão de seu ataque ao textualismo em Significado e compreensão, ele defende a posição de que "não há história das ideias a ser escrita, mas somente uma história necessariamente focada nos agentes que usam as ideias" (Skinner, 1969a, p. 39). A crença na posição contrária derivaria de uma visão em que ideias e conceitos são tidos como portadores de "significados essenciais" e identidades fixas ao longo do tempo. E note-se que o "grande erro" contido nessa posição "reside não somente em procurar pelo 'significado essencial' de uma 'ideia' como algo que permanece o mesmo, mas na própria concepção de que há um significado 'essencial'” (Skinner, 1969a, p. 37).

Vários críticos de Skinner têm compreendido essa recusa da dimensão de continuidade na história dos conceitos como uma prova da falta de historicidade de sua metodologia. Ellen Wood afirma que a "ausência de processo" nas prescrições de Skinner revela uma visão "curiosamente a-histórica" (Wood, 2008, p. 10), enquanto Kenneth Minogue sugere que Skinner, tão cioso em denunciar "mitologias" na história das ideias, teria sucumbido, ele próprio, numa "mitologia da fragmentação" (Minogue, 1988, p. 179). Sem continuidade não há processo e sem uma ideia de processo não se pode compreender a transformação. Por isso um crítico mais recente conclui que o método de Skinner "não pode explicar a mudança". E mesmo reconhecendo que ele tenha "escrito histórias que traçam a mudança conceitual e linguística", tais histórias não eram e não poderiam ser derivadas de seu "método declarado" (Bevir, 1999, p. 48-49). 
Em seu primeiro texto de resposta a essa linha de crítica, Skinner reagiu aos que apontavam a inaptidão de seu método para o estudo da mudança conceitual. O autor se confessa "atônito" em saber de seus críticos que sua abordagem "tornaria impossível mapear" os fenômenos de "inovação e mudança”, e chega mesmo a afirmar que, "ao contrário, eu estou oferecendo os meios - os únicos meios corretos - de exibir o caráter preciso dessas mudanças" (Skinner, 1974, p. 287). Décadas mais tarde, Skinner reafirma que "endossa fortemente a crença de que devemos estar prontos, como historiadores da filosofia, não apenas a admitir o fato da mudança conceitual, mas a torna-lo central em nossa investigação" (2002c, p. 178).

Mas o fato é que o próprio autor continua a alimentar certa ambiguidade sobre esse tema. Em um segundo e mais extenso texto de reposta aos críticos, ele se diz "sem arrependimento" em sua crença de que "não são possíveis histórias de conceitos enquanto tais" (Skinner, 1988, p. 283). Já em uma entrevista de 2007, quando instado a comentar a frase de Ortega Y Gasset, segundo a qual "não há ideias eternas" e "não pode haver uma real história das ideias" (apud Skinner, 2007, p. 106), o historiador de Cambridge responde que "basicamente, concordo com isso apaixonadamente" (2007, p. 106). Em seguida, talvez frustrando a expectativa do entrevistador, Javier Sebastián, um pesquisador associado ao projeto de fusão do contextualismo linguístico com a Begriffsgeschichte (a história dos conceitos de origem germânica), Skinner afirma que "ainda sente que há algo de a-histórico” na abordagem liderada por Reinhart Koselleck, e que esse sentimento talvez seja uma forma de dizer, "uma vez mais, que a tarefa histórica apropriada parece-me aquela de estudar não as histórias das palavras, mas a história dos usos que são feitos dessas palavras em épocas diferentes e em diferentes argumentos" (Skinner, 2007, p. 115). 
Seja qual for a atual posição de Skinner sobre o tema da mudança conceitual, o fato é que suas prescrições metodológicas originais não favoreciam uma abordagem diacrônica na história das ideias. Mas também é fato que essa barreira metodológica não o inibiu de estabelecer como um dos principais objetivos de Fundações apontar "alguns aspectos do processo pelo qual veio a formar-se o moderno conceito de Estado" (Skinner, 1996, p. 9). A centralidade desse objetivo reflete-se até mesmo nos marcos temporais da narrativa. O autor explica que "começa em fins do século XIII" e vai "até o fim do século XVI, por ter sido durante esse período [...] que gradualmente se formaram os principais elementos de um conceito de Estado passível de dizer-se moderno" (Skinner, 1996, p. 9). Parece-me improvável que uma narrativa que se detenha sobre três séculos de conflitos ideológicos faça sentido sem um forte senso de diacronia e uma acurada visão de processo.

Na conclusão do livro, Skinner resume o que considera os principais "pré-requisitos para a formação do conceito de Estado moderno" (Skinner, 1996, p. 617): primeiro, a esfera política passa a ser concebida como um ramo distinto da filosofia moral; segundo, postula-se a "independência de cada regnum ou civitas de todo poder externo e superior"; terceiro, a autoridade suprema é aceita como única e sem rivais em seu próprio território; quarto, o Estado existe exclusivamente para a realização de fins políticos, jamais para fins religiosos (Skinner, 1996, pp. 617-620). Somente quando o conjunto desses pré-requisitos é reunido, o que ocorre por volta do final do século XVI, torna-se possível conceber o Estado "em termos caracteristicamente modernos - como a única fonte da lei e da força legítima dentro de seu território, e como o único objeto adequado da lealdade de seus súditos" (Skinner, 1996, p. 10). A despeito da ambiguidade de Skinner sobre a viabilidade de ideias e conceitos tornarem-se as unidades básicas da investigação histórica, 
não há dúvida de que Fundações representa, ao menos em parte, um notável exercício de história conceitual.

Mas se a narrativa apresentada em Fundações segue por caminhos não previstos ou mesmo interditados na metodologia contextualista, não é menos verdade que a obra se mantém fiel a princípios hermenêuticos assumidos desde os primeiros escritos do autor. Tenho em mente princípios que operam no plano filosófico (não necessariamente no plano metodológico) e orbitam em torno de uma visão da história do pensamento político como uma história de conflitos ideológicos. Essa "hermenêutica do conflito" - para usar a feliz expressão de Charles Taylor (1988, p. 218) - é, a meu ver, o traço mais marcante e constante do conjunto da obra de Skinner. A visão da própria vida política como uma incessante luta por legitimidade é o que subjaz ao intuito do autor de "estabelecer vínculos mais próximos entre as teorias políticas e a vida política” (Skinner, 1996, p. 11).

158 Voltaremos, adiante, a este ponto.

\section{Arqueologia e genealogia}

A relativização do contextualismo radical de Skinner explica-se também pelo encontro do autor com uma crescente legião de críticos de suas prescrições metodológicas. Depois da publicação de Significado e compreensão, o contextualismo linguístico manteve-se por décadas no centro de um intenso debate sobre teoria e método na história do pensamento político (Silva, 2010). Ao mesmo tempo em que defendia suas principais posições, Skinner introduzia refinamentos, nuanças e modificações em suas formulações iniciais. O problema é que tais alterações são introduzidas sub-repticiamente, sem que o autor enuncie com clareza o abandono de posições anteriores. Vê-se isso no longo ensaio de resposta a seus críticos, publicado no final da década de 1980 (Skinner, 1988). O tom da resposta de Skinner soava como uma defesa cerrada de sua metodologia, embora 
seu juízo sobre o decisivo tema da relevância do estudo do passado para o esclarecimento do presente tenha sofrido importantes reformulações. No volume sobre método da trilogia Visões da política (2002c), o autor consolida suas reformulações. Para livrar-se da pecha de "antiquarista", ele foi compelido a deixar claro de que modo o estudo da história do pensamento político é relevante ao entendimento do presente. Mobilizando metáforas arqueológicas, Skinner sustenta que as "escavações" levadas a cabo por historiadores e etnógrafos tem o potencial de tornar "algumas de nossas crenças correntes, digamos, nossos arranjos políticos e morais diretamente questionáveis" (Skinner, 2002c, p. 126). Ou seja, o estudo do passado teria uma função crítica de falsear crenças e opiniões naturalizadas em nossa própria época.

Mas isso não é tudo. Além da função crítica e negativa, a história do pensamento político exerce uma função positiva na formulação da teoria política contemporânea, uma vez que, por meio das referidas "escavações", se é capaz de revelar "tesouros enterrados", dignos de recuperação pelo teórico político da atualidade. E isso porque "ao retornarmos para olhar como esses conceitos eram mobilizados em tradições de pensamento passadas, podemos encontrar uma discussão mais rica dos conceitos que continuamos a empregar" (Skinner, 1997, p. 74). Skinner apresenta como exemplo de descoberta de um desses "tesouros enterrados" o trabalho de James Tully, especialmente a crítica do teórico canadense ao constitucionalismo moderno a partir de uma perspectiva esquecida pelo avanço da fase imperialista da história europeia. Para Skinner, "o tesouro enterrado escavado por Tully revela uma impressionante capacidade para enriquecer, de imediato, os nossos argumentos políticos" (Skinner, 2002c, p. 126). Note-se que o enriquecimento ocorre "de imediato", o que sugere uma contribuição direta do conhecimento do passado para o esclarecimento dos 
problemas presentes, possibilidade outrora rechaçada por Skinner.

Um exemplo ainda mais expressivo do emprego da metáfora arqueológica para justificar a relevância teórica do conhecimento histórico é a reconstrução realizada pelo próprio Skinner da teoria neorromana da liberdade, presente sobretudo em A liberdade antes do liberalismo (1999). O autor afirma ter realizado "um desses atos de escavação" ao estudar "a estrutura, e ao mesmo tempo vindicar a coerência”, da "teoria neorromana dos cidadãos livres e Estados livres" (Skinner, 1999, p. 91). Com isso, ele teria cumprido seu papel de historiador do pensamento, que "é agir como um tipo de arqueólogo, trazendo de volta à superfície tesouros intelectuais enterrados, limpando sua poeira e possibilitando-nos reconsiderar o que pensamos deles" (Skinner, 1999, p. 90).

A reconstrução da teoria neorromana da liberdade con160 solida e eleva a um novo patamar teórico a pesquisa sobre a tradição republicana apenas esboçada em Fundações. O interesse no discurso de legitimação do modo de vida livre das cidades da Itália renascentista é então aprofundado em uma série de estudos sobre Maquiavel e a liberdade republicana, publicados entre o início dos anos 1980 e o início dos anos 1990 (Skinner, 1981; 1983; 1984; 1991a; 1991b). Nesses textos, Skinner promove um movimento explícito no sentido de mobilizar a história das ideias para um engajamento mais direto com a teoria política contemporânea. Em um ensaio sobre a "ideia de liberdade negativa", sugestivamente subintitulado "perspectivas histórica e filosófica", ele fixa como objetivo "explorar um possível meio de ampliar nosso presente entendimento de conceitos que empregamos no argumento político e social” (Skinner, 1984, p. 193).

Se há uma intenção que resume o espírito desse movimento de Skinner, ela consiste em sugerir uma alternativa à dicotomia entre liberais e comunitaristas, dicotomia que 
dominou o debate na teoria política normativa nas últimas décadas do século XX. "O ideal republicano de liberdade" (título de outro ensaio desse período), que Skinner atribui a Maquiavel - mas também a autores ingleses do século XVII, como Milton e Harrington - é mobilizado em um esforço de contestação direta de autores contemporâneos como Berlin, Ralws e Dworkin de um lado, e Arendt, Taylor e MacIntyre de outro, representantes, respectivamente, dos polos liberal e comunitarista do debate que configura o contexto linguístico em que se deve compreender o movimento de Skinner (Skinner, 1991b). Referindo-se à afirmação de MacIntyre (1981, p. 2) de que a "oposição moral crucial é entre o individualismo liberal [...] e a tradição aristotélica”, Skinner nos informa que intenciona "sugerir que esta é uma falsa dicotomia” (Skinner, 1991b, p. 293). Tal dicotomia traduzia-se também na oposição entre liberdade negativa e liberdade positiva, para usar os termos reelaborados por Isaiah Berlin no final dos anos 1950 (Berlin, 2002). Skinner esclarece que embora a liberdade republicana defina-se em termos negativos - a ausência de impedimentos às escolhas individuais -, ela difere da concepção liberal em dois importantes aspectos: não compreende a lei como uma necessária restrição à liberdade e considera a participação política dos cidadãos como instrumento indispensável, à luz das lições da história, para a defesa das liberdades individuais.

Não obstante essas diferenças com a visão liberal, os textos sobre Maquiavel e a liberdade republicana publicados até o início da década de 1990 revelam uma disposição mais voltada a enfatizar a distinção entre republicanismo e comunitarismo do que em fazer do republicanismo uma alternativa teórica à tradição liberal (Silva, 2015). Excetuando-se o valor instrumental da participação política na tradição republicana, ausente no liberalismo anatematizado por Skinner, pouco resta para diferenciar a liberdade republicana da liberdade negativa liberal. Na verdade, conforme veredito 
do próprio Skinner, ambas são no essencial a mesma coisa: a ausência de impedimento à realização de fins individuais. Por isso, ele argumenta, numa formulação mais filosófica que histórica, que Maquiavel "não tem objeções à constatação hobbesiana de que a capacidade de perseguir tais fins sem obstrução é o que determina a 'liberdade' propriamente dita" (Skinner, 1984, p. 217). Seria então o republicanismo algo como um liberalismo em trajes participativistas?

Em Liberdade antes do liberalismo o autor reúne argumentos para uma resposta negativa à questão acima. Em termos analíticos, a liberdade republicana (ou neorromana, como prefere Skinner) continua a ser concebida como um tipo de liberdade negativa, pois seu critério de definição segue sendo a ausência, não a presença de algo. Mas agora seu núcleo definidor distingue-se com clareza do núcleo da concepção liberal. Ou seja, o elemento necessariamente ausente para a existência da liberdade não é a coerção, ou a 162 interferência indiscriminada nas escolhas individuais, mas a dependência, que se define como um tipo particular de interferência. Ser livre é não estar à mercê da interferência arbitrária de terceiros. Em uma palavra, ser livre é não ser dominado. Vale ressaltar que essa formulação se deve, em grande medida, ao progressivo intercâmbio entre Skinner e o filósofo político Philip Pettit. Trata-se de uma relação de influência mútua. Ao mesmo tempo em que Pettit toma como ponto de partida a história da tradição republicana narrada por Skinner, este revê o resultado de sua narrativa à luz dos refinamentos conceituais introduzidos por Pettit (Silva, 2008). Com a ajuda do filósofo, o historiador encontra enfim sua "terceira concepção de liberdade" (Skinner, 2001, p. 237): "a liberdade como ausência de poder arbitrário” (Skinner, 2008, p. 83).

Aqueles familiarizados com as prescrições metodológicas do contextualismo linguístico dificilmente poderiam ignorar o ruído introduzido no conjunto do receituário 
pela hipótese de que a reconstrução histórica de uma visão da liberdade situada nos contextos dos séculos XVI e XVII possa ser considerada a saída para um debate teórico-normativo no contexto das últimas décadas da atualidade. O que dizer da advertência proferida em Significado e compreensão, segundo a qual "exigir da história do pensamento político uma solução para nossos problemas imediatos é cometer não apenas uma falácia metodológica, mas também algo como um erro moral" (Skinner, 1969a, p. 53)? E como compreender o conselho, decorrente da advertência, de que a única maneira de evitarmos esse duplo equívoco é "aprendermos a pensar por nós mesmos" (Skinner, 1969a, p. 52)?

A liberdade antes do liberalismo consolida uma espécie de virada normativa na obra de Skinner, mas frutos ainda mais representativos dessa virada podem ser observados em trabalhos subsequentes, sobretudo em seu estudo sobre a evolução do conceito de liberdade em Hobbes. Skinner argumenta que a fórmula definida no Leviatã resultou em uma mudança conceitual revolucionária e em poderosa arma de luta ideológica contra o republicanismo. Hobbes "venceu a batalha" (Skinner, 2010, p. 197), deixando como herança uma concepção de liberdade que, "no nosso mundo contemporâneo", tem sido "amplamente tratada como um artigo de fé” (Skinner, 2010, p. 194). Aqui, uma vez mais se coloca a questão: a sugestão de que a concepção de liberdade desenvolvida por Hobbes no longínquo século XVII representa "hoje" um "artigo de fé" não nos levaria de volta ao desvio do "anacronismo"? Há quem acredite que sim, considerando "estranho encontrar um escritor que começou pela insistência na especificidade histórica de cada período agora vindo a defender o tipo de categoria meta-histórica maniqueísta que ele tanto deplorou" (Dienstag, 2009, p. 703). 
Mas não é de hoje que Skinner reconhece que passou a encontrar "mais coisas na perspectiva de uma tradição e, consequentemente, de uma continuidade intelectual do que costumava encontrar", e que isso o tem levado a ver "mais promissoramente do que costumava ver" o valor atual do engajamento crítico "com nossos antepassados e grandes pensadores, ao menos quanto a alguns conceitos-chave que continuam a estruturar nossa vida em comum" (Skinner, 2002b, p. 55). É duvidoso que essa alteração de enfoque, por si só, abra as portas ao anacronismo, mas não há dúvida de que se trata de uma alteração auspiciosa a todos os envolvidos na prospecção de uma teoria política historicamente informada. Com a condição de não se perder de vista o fenômeno da mudança conceitual, o foco dirigido às continuidades ou às continuidades vestidas de mudança contribui para enriquecer nosso entendimento tanto do presente como do passado. Sem o sentido de permanência, o estudo 164 dos autores clássicos nada teria a contribuir para a teoria política - e poucos duvidam de que, neste caso, estaríamos dilapidando um precioso patrimônio ${ }^{3}$.

E o que dizer da opinião dos que consideram "desconcertante" que grande parte dos escritos de Quentin Skinner, nos estágios mais adiantados de sua carreira, seja informada por seus "compromissos políticos e filosóficos fortemente assumidos" (Collins, 2009, p. 365)? De fato, à medida que Skinner vai aprofundando sua pesquisa sobre o republicanismo e constatando a viabilidade atual dessa tradição da filosofia política, ele próprio vai assumindo seu lugar no debate normativo. Sem abandonar os recursos e a prática de historiador, ele vai assumindo paulatinamente o papel de

\footnotetext{
3 Conforme um defensor da fusão entre história do pensamento e teoria política definiu recentemente, "clássica é uma obra que, embora escrita em um contexto histórico específico, demonstra continuamente a capacidade de informar produtivamente a formação, o pensamento, a percepção e talvez os compromissos dos leitores situados em épocas e lugares dramaticamente diferentes daqueles do autor" (Green, 2015, p. 438).
} 
teórico da política. Na introdução do volume metodológico de Visões da política, o autor expressa de maneira renovada sua crença recorrente de que "os princípios que governam nossa vida política e moral têm sido geralmente disputados de uma maneira mais reminiscente de um campo de batalha do que de uma sala de seminário" (Skinner, 2002c, p. 7). Por isso ele afirma ver "com uma certa ironia" aqueles filósofos políticos e morais que nos apresentam visões abrangentes de justiça, liberdade e outros valores estimados "a maneira de analistas desapaixonados situados acima do campo de batalha"; a ironia está no fato de que "a batalha é tudo o que há” (Skinner, 2002c, p. 7).

Essa visão sobre a centralidade das disputas por poder e legitimidade na vida política não precisa e não deve limitar-se a um único método. Por isso a "hermenêutica do conflito" de Skinner, após servir-se, primeiro, do contextualismo e, depois, da arqueologia, mais recentemente passou a servir-se também da genealogia. Não é difícil perceber as motivações dessa "virada genealógica" (Lane, 2012) na metodologia de Skinner. Tanto quanto o contextualismo e a arqueologia, a genealogia consiste em uma técnica de investigação histórica, um modo de se estudar o passado. Mas o recurso à genealogia atende melhor o atual interesse teórico do autor, porque ilumina com maior eficácia os aspectos de continuidade, conflito e contingência na história da teoria política.

Em Uma genealogia do Estado moderno - texto que o autor acredita conter sua reflexão mais acabada sobre o conceito de Estado (Skinner, 2011, p. 278) -, Skinner escreve que "quando traçamos a genealogia de um conceito [...] equipamo-nos com um instrumento útil para refletir criticamente sobre a forma como esse conceito é hoje utilizado". A investigação genealógica parte do presente em direção ao passado, procurando iluminar "as diferentes maneiras como determinado conceito terá sido utilizado em épocas 
anteriores" (Skinner, 2009, p. 325). Não se trata aqui de estudar um passado já totalmente esgotado, mas um passado que, de algum modo, se atualiza no presente. A genealogia ocupa-se não apenas das origens de um conceito, mas do processo que resultou nos usos contemporâneos de tal conceito.

Skinner recorre às considerações de Nietzsche (1998) na Genealogia da moral para corrigir suas conclusões anteriores sobre a história do conceito de Estado moderno. Como vimos, em Fundações, o Estado moderno é definido de uma única maneira: nos termos weberianos do monopólio da coerção legítima exercida em determinado território. Agora, Skinner ecoa a frase de Nietzsche (1998, p. 68) segundo a qual "definível é apenas aquilo que não tem história", para concluir que "investigar a genealogia do Estado é o mesmo que descobrir que nunca existiu um conceito único que a palavra 'Estado' correspondesse”. Não se trata de negar que determinadas definições alcancem hegemonia em determinadas épocas, mas sim de "sugerir que qualquer termo moral ou político [...] que tenha ficado tão profundamente enleado em disputas ideológicas, durante tanto tempo, resiste necessariamente a qualquer tentativa de definição" (Skinner, 2009, p. 326). Desse modo, o recurso à genealogia serve não apenas para Skinner trazer à luz o tema da continuidade, mas também para atualizar sua visão da centralidade do conflito na vida política.

Por fim, a genealogia serve também ao propósito de Skinner de afastar qualquer traço de teleologia remanescente de seus trabalhos anteriores. Bem mais enfaticamente que os métodos contextualista e arqueológico, o método genealógico realça o papel da contestabilidade e da contingência na história conceitual. Assim, à medida em que a genealogia de um conceito é desvelada, tornam-se patentes “o caráter contingente e contestável do conceito, ou seja, a 
impossibilidade de demonstrar que possui qualquer essência ou fronteiras naturais" (Skinner, 2009, p. 326).

\section{Conclusão}

A trajetória intelectual de Quentin Skinner revela um progressivo esforço de integração das contribuições da história do pensamento político à teoria política contemporânea, inclusive a de natureza mais normativa. Ao longo da década de 1960, em seus primeiros estudos substantivos e nas formulações de método que lhes são coetâneas, Skinner mobilizou o contextualismo linguístico para demarcar a fronteira entre história e teoria. Os historiadores do pensamento político eram orientados a ater-se exclusivamente ao contexto do debate em que os autores cujos textos se pretende compreender estavam efetivamente imersos. As preocupações "presentistas" deviam ser deixadas aos filósofos. Com o passar do tempo, essa fronteira foi recorrentemente ultrapassada e tornada mais fluida, favorecendo a integração entre história e teoria. Evidências a esse respeito já podiam ser observadas no modo como os principais estudos históricos do autor, sobretudo a partir de Fundações, passam largo de - e até mesmo colidem com - algumas de suas prescrições metodológicas originais.

Movido pela necessidade de justificar metodologicamente a utilidade do estudo do passado para o esclarecimento do presente, Skinner é levado a uma revisão de seu contextualismo original. O trabalho do historiador passa a ser concebido analogamente ao trabalho do arqueólogo e, mais recentemente, do genealogista. A arqueologia revela "tesouros enterrados" e a genealogia elucida os processos conflituosos e contingentes que nos legaram os conceitos que continuamos a empregar na atualidade. Não obstante as variações metodológicas, a visão skinneriana da vida política como o lugar de incessantes conflitos ideológicos mantém-se constante no conjunto da obra do autor. Talvez seja 
possível afirmar que as alterações na metodologia decorrem do esforço de atualização de filosofia política do autor. A trajetória de Skinner ilustra a afirmação de John Pocock, outro protagonista do contextualismo linguístico, de que "a história do pensamento político tem uma constante tendência de tornar-se filosofia" (Pocock, 1962, p. 187). Podemos acrescentar, a despeito do que acreditavam inicialmente os contextualistas, que isso não é necessariamente ruim, desde que não se perca de vista o caminho de volta, ou seja, a tendência de a filosofia tornar-se história do pensamento.

\section{Ricardo Silva}

é professor titular de Teoria Política do Departamento de Sociologia e Ciência Política da Universidade Federal de Santa Catarina e bolsista de produtividade em pesquisa do Conselho Nacional de Desenvolvimento Científico e Tecnológico.

\section{Bibliografia}

BERLIN, I. 2002. Dois conceitos de liberdade. In: HARDY, H.;

HAUSHEER, R. (orgs.). Isaiah Berlin: estudos sobre a humanidade. São Paulo: Companhia das Letras, pp. 226-271.

BEVIR, M. 1999. The logic of the history of ideas. Cambridge, MA: Cambridge

University Press.

. 2009. Contextualism: from modernist method to post-analytic

historicism. Journal of the Philosophy of History, v. 3, n. 3, pp. 211-224.

BEVIR, M.; ADCOCK, R. 2007. The remaking of political theory. In:

ADCOCK, R.; BEVIR, M.; STIMSON, S. (eds.). Modern political science:

Anglo-American exchanges since 1880. Princeton, NJ: Princeton University

Press, pp. 209-233.

BOUCHER, D. 1985. Texts in context: revisionist methods for studying the history of ideas. Dordrecht: Martius Nijhoff.

. 1986. Conversation and political thought. New Literary History,

v. 18 , n. 1, pp. 59-75.

COLLINS, J. R. 2009. Quentin Skinner's Hobbes and the neo-republican

project. Modern Intellectual History, v. 6, n. 2, pp. 343-367. 
DIENSTAG, J. F. 2009. Man of peace: Hobbes between politics and science. Political Theory, v. 37, n. 5, pp. 694-705.

FERES JÚNIOR, J. 2005. De Cambridge para o mundo, historicamente: revendo a contribuição metodológica de Quentin Skinner. Dados: Revista de Ciências Sociais, v. 48, n. 3, pp. 655-680.

GREEN, J. E. 2015. Political theory as both philosophy and history: a defense against methodological militancy. Annual Review of Political Science, v. 18, pp. 425-441.

HARLAN, D. 1989. Intellectual history and the return of literature. The American Historical Review, v. 94, n. 3, pp. 581-609.

LANE, M. 2012. Doing our thinking for ourselves: on Quentin Skinner's genealogical turn. Journal of the History of Ideas, v. 73, n. 1, pp. 71-82.

LASLETT, P. 1956. Introduction. In: LASLETT, P. (ed.). Philosophy, politics, and society. Oxford: Blackwell, pp. vii-xv.

. 1960. Introduction. In: LOCKE, J. Two treatises on government. Cambridge, MA: Cambridge University Press, pp. 3-153.

MACINTYRE, A. C. 1981. After virtue: a study in moral theory. London: Duckworth.

MINOGUE, K. R. 1988. Method in intellectual history: Quentin Skinner foundations. In: TULLY, J. (ed.). Meaning and context: Quentin Skinner and his critics. Cambridge, UK: Polity, pp. 176-193.

NIETZSCHE, F. 1998 [1887]. Genealogia da moral: uma polêmica. Tradução de Paulo César de Souza. São Paulo: Companhia das Letras.

POCOCK, J. 1962. The history of political thought: a methodological Enquiry. In: LASLETT, P.; RUNCIMAN, W. G. (eds.). Philosophy, Politics and Society. Oxford: Blackwell, pp. 183-202.

POCOCK, J. G. A. 2004. Quentin Skinner: the history of politics and the politics of history. Common Knowledge, v. 10, n. 3, pp. 532-550.

PALONEN, K. 2002. The history of concepts as a style of political theorizing: Quentin Skinner and Reinhart Koselleck's subversion of normative political theory. European Journal of Political Theory, v. 1, n. 1 pp. 91-106.

. 2003. Quentin Skinner: history, politics, rhetoric. Cambridge, UK: Polity.

RICOEUR, P. 1979. The model of the text: meaningful action considered as a text. In; RABINOW, P.; SULLIVAN, W. M. (eds.). Interpretive social science: a reader. Berkeley: University of California Press, pp. 73-102.

SEIDMAN, S. 1983. Beyond presentism and historicism: understanding the history of social sciences. Sociological Inquiry, v. 53, n. 1, pp. 77-94. 
SILVA, R. 2008. Liberdade e lei no neo-republicanismo de Skinner e Pettit. Lua Nova, n. 74, pp. 151-194.

2010. O contextualismo linguístico na história do pensamento político: Quentin Skinner e o debate metodológico contemporâneo. Dados, v. 53, n. 2, pp. 299-335. 2015. Visões da liberdade: republicanismo e liberalismo no debate teórico contemporâneo. Lua Nova, n. 94, pp. 181-215.

SKINNER, Q. 1964. Hobbes' "Leviathan”. The Historical Journal, v. 7, n. 2, pp. 321-333.

1965. Hobbes on sovereignty: an unknown discussion. Political Studies, v. 13, n. 2, pp. 213-218. 1966a.The limits of historical explanation. Philosophy, v. 41, n. 157, pp. 199-215.

1966b. Thomas Hobbes and his disciples in France and England.

Comparative Studies in Society and History, v. 8, n. 2, pp. 153-167. . 1966c. The ideological context of Hobbes' political thought. The Historical Journal, v. 9, n. 3, pp. 286-317. 1969a. Meaning and understanding in the history of ideas. History and Theory, v. 8, n. 1, pp. 3-53. 1969b. Thomas Hobbes and the nature of the early Royal Society.

The Historical Journal, v. 12, n. 2, pp. 217-239. 1974. Some problems in the analysis of political thought and action. Political Theory, v. 2, n. 3, pp. 277-303. . 1981. Machiavelli. Oxford: Oxford University Press. 1983. Machiavelli on the maintenance of liberty. Politics, v. 18, n. 2, pp. 3-15.

1984. The idea of negative liberty: philosophical and historical perspectives. In: RORTY, R.; SCHNEEWIND, J. B.; SKINNER, Q. (eds.). Philosophy in history. Cambridge, MA: Cambridge University Press, pp. 193-222.

1988. A reply to my critics. In: TULLY, J. (ed.). Meaning and context: Quentin Skinner and his critics. Cambridge, UK: Polity, pp. 231-288.

1991a. Machiavelli's discorsi and the pre-humanist origins of republican ideas. In: BOCK, G.; SKINNER, Q.; VIROLI, M. (eds.). Machiavelli and republicanism. Cambridge, MA: Cambridge University Press, pp. 121-142. 1991b. The republican ideal of political liberty. In: BOCK, G.; SKINNER, Q.; VIROLI, M. (eds.). Machiavelli and republicanism. Cambridge, MA: Cambridge University Press, pp. 293-309. 
1996 [1978]. As fundações do pensamento político moderno. Tradução de Renato Janine Ribeiro e Laura Teixeira Motta. São Paulo:

Companhia das Letras. 1997. An interview with Quentin Skinner. Cogito, v. 11, n. 2, pp. 69-76.

1999. A liberdade antes do liberalismo. Tradução de Raul Fiker. São Paulo: Unesp. 2001. A third concept of liberty. Proceedings of the British Academy, v. 117 , pp. 237-268.

2002a. Quentin Skinner (interview). In: PALLARES-BURKE, M.

L. (ed.). The new history: confessions and conversations. Cambridge, UK: Polity, pp. 212-240.

. 2002b. Quentin Skinner on encountering the past (interview).

Finnish Yearbook of Political Thought, v. 6, pp. 34-63.

2002c. Visions of Politics: regarding method. Cambridge, MA:

Cambridge University Press. v. 1. . 2006. Surveying The Foundations: a retrospect and reassessment.

In: BRETT, A. TULLY, J.; HAMILTON-BLEAKLEY, H. (eds.). Rethinking The Foundations of Modern Political Thought. Cambridge, MA: Cambridge University Press, pp. 236-261.

. 2007. Intellectual history, liberty and republicanism: an interview

with Quentin Skinner. Contributions to the History of Concepts, v. 3, n. 1, pp. 103-123. 2008. Freedom as the absence of arbitrary power. In: LABORDE,

C.; MAYNOR, J. W. (eds.). Republicanism and political theory. London: Blackwell, pp. 83-101. . 2009. A genealogy of the modern state. Proceedings of British

Academy, v. 162, pp. 325-370. . 2010. Hobbes e a liberdade republicana. Tradução de Modesto

Florenzano. São Paulo: Unesp. 2011. An interview with Quentin Skinner. Contemporary Political Theory, v. 10, n. 2, pp. 273-285.

TAYLOR, C. 1988. The hermeneutics of conflict. In: TULLY, J. (ed.).

Meaning and context: Quentin Skinner and his critics. Cambridge, UK:

Polity, pp. 218-228.

VINCENT, A. 2004. The nature of political theory. Oxford: Oxford University Press.

WOOD, E. M. 2008. Citizens to lords: a social history of Western political thought from Antiquity to the Middle Ages. London: Verso. 


\section{DA HISTÓRIA DO PENSAMENTO POLÍTICO À TEORIA POLÍTICA HISTÓRICA: VARIAÇÕES DA HERMENÊUTICA DO CONFLITO DE QUENTIN SKINNER}

RICARD0 SILVA

Resumo: Visando a apresentação de um caso exemplar da abordagem histórica da teoria política, este artigo examina momentos decisivos da trajetória intelectual de Quentin Skinner, de suas primeiras publicações às mais recentes. Observa-se que, com o passar das décadas, Skinner evolui de uma posição adversa para uma posição favorável ao intercâmbio entre a história do pensamento político e a teoria política contemporânea. Em seu esforço de provar a relevância do passado para a intelecção do presente, o autor afasta-se de suas prescrições contextualistas mais extremadas e passa a conceber seu método histórico nos termos da arqueologia e, mais recentemente, da genealogia. Argumenta-se que, a despeito de suas diferenças, as várias fases da metodologia de Skinner têm em comum o fato de derivarem de uma filosofia que situa o conflito ideológico no centro da vida política.

Palavras-chave: Teoria política histórica; Quentin Skinner; Contextualismo; Arqueologia; Genealogia; Conflito.

\section{FROM HISTORY OF POLITICAL THOUGHT TO HISTORICAL POLITICAL THEORY: VARIATIONS OF QUENTIN SKINNER'S HERMENEUTICS OF CONFLICT}

Abstract: Aiming at presenting an exemplary case of the historical approach to political theory, this article examines key moments of Quentin Skinner's intellectual career, from his earliest publications to the most recent ones. It shows that through the years Skinner has evolved from an adverse position to a favorable position regarding the exchange between the history of political thought and 
contemporary political theory. In his effort to prove the relevance of the past to the intellection of the present, that author departs from his more extreme contextualist prescriptions and begins to conceive his historical method in terms of archeology and, more recently, genealogy. It is argued that, despite their differences, the several phases of Skinner's methodology have in common the fact that they derive from a philosophy that places ideological conflict at the center of political life.

Keywords: Historical political theory; Quentin Skinner; Contextualism; Arqueology; Genealogy; Conflict.

Recebido: 26/04/2017 Aprovado: 01/07/2017 